\title{
Effects of sildenafil citrate on peripheral fatigue and exercise performance after exhaustive swimming exercise in rats
}

\author{
Tae-Woon Kim', Sang-Seo Park', Bo-Kyun Kim² , Young-Je Sim³ ${ }^{3}$ Mal-Soon Shin ${ }^{4, *}$ \\ 'Department of Physiology, College of Medicine, Kyung Hee University, Seoul, Korea \\ 2Department of Emergency Technology, College of Health Science, Gachon University, Incheon, Korea \\ ${ }^{3}$ Department of Physical Education, Kunsan National University, Gunsan, Korea \\ ${ }^{4}$ College of Culture and Sports, Division of Global Sport Studies, Korea University, Sejong, Korea
}

Sildenafil citrate is a potent and selective inhibitor of phosphodiesterase type- 5 used to treat erectile dysfunction. We investigated the effects of sildenafil citrate treatment on peripheral fatigue and exercise performance after exhaustive swimming exercise in rats. The rats in the sildenafil citrate-treated groups received sildenafil citrate orally once a day for 14 consecutive days at respective dosage. On the 14 days after starting experiment, each animal was submitted to swimming test with intensity equivalent to overload. The exhaustion was defined as a state in which coordinated movements did not return to the water surface for breathing within $10 \mathrm{sec}$. Western blot for monocarboxylate transporter (MCT)1, MCT4, and neuronal nitric oxide synthase (nNOS) were performed. Exhaustive swimming exercise decreased time of exhaustion and increased lactate concentration, however, sildenafil citrate en- hanced time of exhaustion and decreased lactate concentration. Exhaustive swimming exercise increased MCT1 and MCT4 expressions in the gastrocnemius muscles and sildenafil citrate further enhanced MCT1 and MCT4 expressions in the exhaustive swimming exercise rats. Exhaustive swimming exercise decreased nNOS expression in the gastrocnemius muscles and sildenafil citrate enhanced nNOS expression in the exhaustive swimming exercise rats. The most potent effect appeared in the $20-\mathrm{mg} / \mathrm{kg}$ sildenafil citrate. Sildenafil citrate might be proposed as a potential ergogenic aid through antiperipheral fatigue.

Keywords: Sildenafil citrate, Peripheral fatigue, Exhaustive swimming exercise, Monocarboxylate transporter, Neuronal nitric oxide synthase

\section{INTRODUCTION}

Fatigue is classified into central and peripheral fatigue. The peripheral fatigue is caused by lactate accumulation through anaerobic glycolysis (Wan et al., 2017). Lactate is one of the glycolytic pathway products originating via the action of lactate dehydrogenase on pyruvate, which is facilitated by the proton-linked monocarboxylate transporter (MCT) (Sun et al., 2017).

MCTs are transporters of monocarboxylates such as lactate and pyruvate, which play a major role in lactate metabolism. MCTs constitute a family of 14 transporters and the first four members (MCT1-MCT4) carry single-carboxylate molecules across the bio- logical membranes (Halestrap, 2013). In skeletal muscle, MCT1 and MCT4 play an important role as lactate transporter involved in the regulation of lactate flux across the plasma membrane (Bonen, 2001). MCT1 is a high-affinity lactate transporter predominantly present in oxidative fibers, whereas MCT4 is a low-affinity lactate transporter in glycolytic fibers (Benton et al., 2004).

Nitric oxide (NO) is synthesized from L-arginine molecular oxygen as substrate via the members of nitirc oxide synthase (NOS) (Calabrese et al., 2007). Several isoforms of NOS exist and fall into three major classes: inducible NOS (iNOS), endothelial NOS (eNOS), and neuronal NOS (nNOS). Of these, nNOS is expressed in central nervous system and peripheral nervous system such as
${ }^{\star}$ Corresponding author: Mal-Soon Shin (iD https://orcid.org/0000-0002-7462-2211 College of Culture and Sports, Division of Global Sport Studies, Korea University, 2511 Sejong-ro, Sejong 30019, Korea

E-mail: malsoon@korea.ac.kr

Received: October 15, 2019 / Accepted: November 20, 2019
This is an Open Access article distributed under the terms of the Creative Commons Attribution Non-Commercial License (http://creativecommons.org/licenses/by-nc/4.0/) which permits unrestricted non-commercial use, distribution, and reproduction in any medium, provided the original work is properly cited. 
skeletal muscle, and lung epithelia (Förstermann and Sessa, 2012). $\mathrm{nNOS}$ is the major source of NO in skeletal muscle cells (Percival et al., 2010; Stamler and Meissner, 2001). Reduced nNOS exacerbates the fatigue after exercise (Kobayashi et al., 2008).

Sildenafil citrate is a potent and selective inhibitor of phosphodiesterase type-5 (PDE-5) to treat erectile dysfunction (Ricart et al., 2005). PDE-5 is highly expressed in smooth muscle, heart muscle and skeletal muscle (Corbin and Francis, 2002). The possibility that alteration of cyclic guanosine monophosphate (cGMP)-related PDE may represent a novel strategy for the improvement of exercise performance has been suggested (Olfert et al., 2011). Several studies suggested the effect of PDE-5 inhibitors on exercise performance (Hsu et al., 2006; Kloner, 2004; Lewis et al., 2007). Sildenafil citrate improved exercise capacity in subjects with cardiopulmonary disease or pulmonary hypertension (Kloner, 2004; Lewis et al., 2007) and in healthy subjects in hypoxia (Faoro et al., 2007; Hsu et al., 2006). PDE-5 inhibitor decreased activation of the hypothalamus-pituitary-adrenal axis during exercise by NO pathway (Di Luigi et al., 2012). Administration of the PDE5 inhibitor sildenafil increased protein synthesis and reduced fatigue in human skeletal muscle (Sheffield-Moore et al., 2013).

However, the effects of sildenafil on exercise performance in relation to peripheral fatigue remains controversial. Therefore, we investigated effects of sildenafil citrate treatment on peripheral fatigue and exercise performance after exhaustive swimming exercise in rats.

\section{MATERIALS AND METHODS}

\section{Animals}

Adult male Sprague-Dawley rats (8 weeks old) were used in this experiment. The experimental procedure was performed in accordance with the animal care guidelines of the National Institutes of Health and the Korean Academy of Medical Sciences. The rats were randomly divided into four groups ( $\mathrm{n}=10$ in each group): the control group, the exhaustive exercise group, the exhaustive exercise and $20-\mathrm{mg} / \mathrm{kg}$ sildenafil citrate-treated group, and the exhaustive exercise and $40-\mathrm{mg} / \mathrm{kg}$ sildenafil citrate-treated group. The rats in the sildenafil citrate-treated groups received sildenafil citrate (Sigma Chemical Co., St. Louis, MO, USA) orally once a day for 14 consecutive days at respective dosage.

\section{Exhaustive swimming exercise}

On the 14 days after starting experiment, each animal was submitted to exhaustive swimming test with intensity equivalent to overload (a metal ring weight attached to the animal's torso) of $10 \%$ of the body weight (Ding et al., 2009). The exhaustion was defined as a state in which coordinated movements did not return to the water surface for breathing within $10 \mathrm{sec}$.

\section{Lactate analysis}

Blood samples $(5 \mu \mathrm{L})$ were collected from a cut at the tip of the tail after all-out swim exercise. Blood lactate concentrations were measured using portable lactate analyzer (KDK Corp., Kyoto, Japan).

\section{Western blot analysis}

Western analysis was performed, according to the previously described method (Shin et al., 2017). Dorsal raphe tissues were dissected. Sample tissues were stored at $-70^{\circ} \mathrm{C}$ until analysis. The tissues were lysed in ice-cold lysate buffer containing $50 \mathrm{mM}$ HEPES (pH, 7.5), $150 \mathrm{mM} \mathrm{NaCl}, 10 \%$ glycerol, 1\% Triton $\mathrm{X}-100,1.5 \mathrm{mM}$ magnesium chloride hexahydrate, $1 \mathrm{mM}$ ethyleneglycol-bis-( $\beta$-aminoethyl ether)-N,N'-tetraacetic acid, $1 \mathrm{mM}$ phenylmethylsulfonyl fluoride, $2-\mu \mathrm{g} / \mathrm{mL}$ leupeptin, $1-\mu \mathrm{g} / \mathrm{mL}$ pepstatin, $1 \mathrm{mM}$ sodium orthovanadate, and $100 \mathrm{mM}$ sodium fluoride, after which the mixture was incubated for $30 \mathrm{~min}$ at $4^{\circ} \mathrm{C}$. The protein concentration was measured using a Bio-Rad colorimetric protein assay kit (Bio-Rad, Hercules, CA, USA). Protein of $30 \mu \mathrm{g}$ was separated on sodium dodecyl sulfate-polyacrylamide gels and transferred onto a nitrocellulose membrane (Whatman, Clifton, NJ, USA). Mouse anti- $\beta$ actin (1:1,000; Santa Cruz Biotechnology, Santa Cruz, CA, USA), rabbit anti-MCT1 antibody (1:1,000; Santa Cruz Biotechnology), rabbit anti-MCT4 (1:1,000; Santa Cruz Biotechnology), and anti-mouse nNOS (1:1000; Santa Cruz Biotechnology) were used as a primary antibody. A horseradish peroxidase-conjugated anti-mouse secondary antibody was used for $\beta$-actin and nNOS, and an anti-rabbit secondary antibody was used for MCT1 and MCT4. Band detection was performed using the enhanced chemiluminescence detection system (Santa Cruz Biotechnology). The bands were quantified using an Image-Pro Plus computer-assisted image analysis system (Media $\mathrm{Cy}$ bernetics Inc., Bethesda, MD, USA).

\section{Statistical analysis}

Differences among the groups were evaluated using IBM SPSS Statistics ver. 23.0 (IBM Co., Armonk, NY, USA) by the one-way analysis of variance followed by Duncan post hoc test. All values are expressed as the mean \pm standard error of the mean. Statistically significant differences were established at $P<0.05$. 


\section{RESULTS}

\section{Effect of sildenafil citrate on exhaustive swimming time}

Exhaustive swimming time is presented in Fig. 1. Exhaustive swimming time was increased in the exhaustive exercise and sildenafil citrate-treated groups than exhaustive swimming exer-

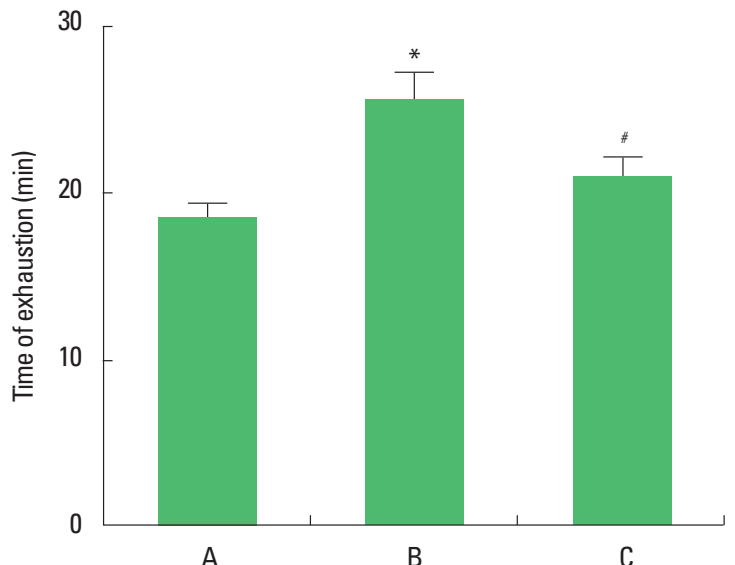

Fig. 1. Effects of sildenafil citrate on exhaustive swimming time. A, exhaustive exercise group; $\mathrm{B}$, exhaustive exercise and $20-\mathrm{mg} / \mathrm{kg}$ sildenafil treatment group; $\mathrm{C}$, exhaustive exercise and $40-\mathrm{mg} / \mathrm{kg}$ sildenafil treatment group. ${ }^{*} P<0.05 \mathrm{com}-$ pared to the exhaustive exercise group. ${ }^{*} P<0.05$ compared to the exhaustive exercise and $20-\mathrm{mg} / \mathrm{kg}$ sildenafil treatment group. cise group. The significant increasing effect on exhaustive swimming time appeared in the $20-\mathrm{mg} / \mathrm{kg}$ sildenafil citrate $(P<0.05)$.

\section{Effect of sildenafil citrate on lactate concentration}

The lactate concentration is shown in Fig. 2. Exhaustive swimming exercise increased lactate concentration $(P<0.05)$ and that

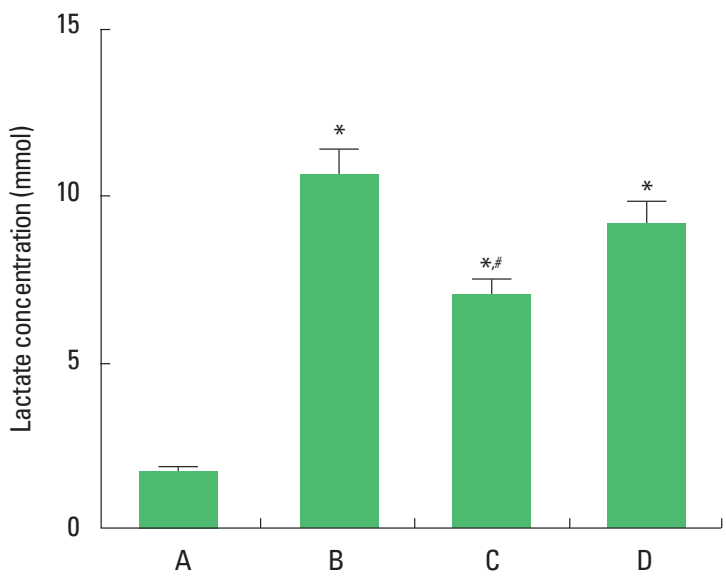

Fig. 2. Effects of sildenafil citrate on lactate concentration. A, control group; $B$, exhaustive exercise group; $\mathrm{C}$, exhaustive exercise and $20-\mathrm{mg} / \mathrm{kg}$ sildenafil treatment group; $D$, exhaustive exercise and $40-\mathrm{mg} / \mathrm{kg}$ sildenafil treatment group. ${ }^{*} P<0.05$ compared to the control group. ${ }^{\#} P<0.05$ compared to the exhaustive exercise group.
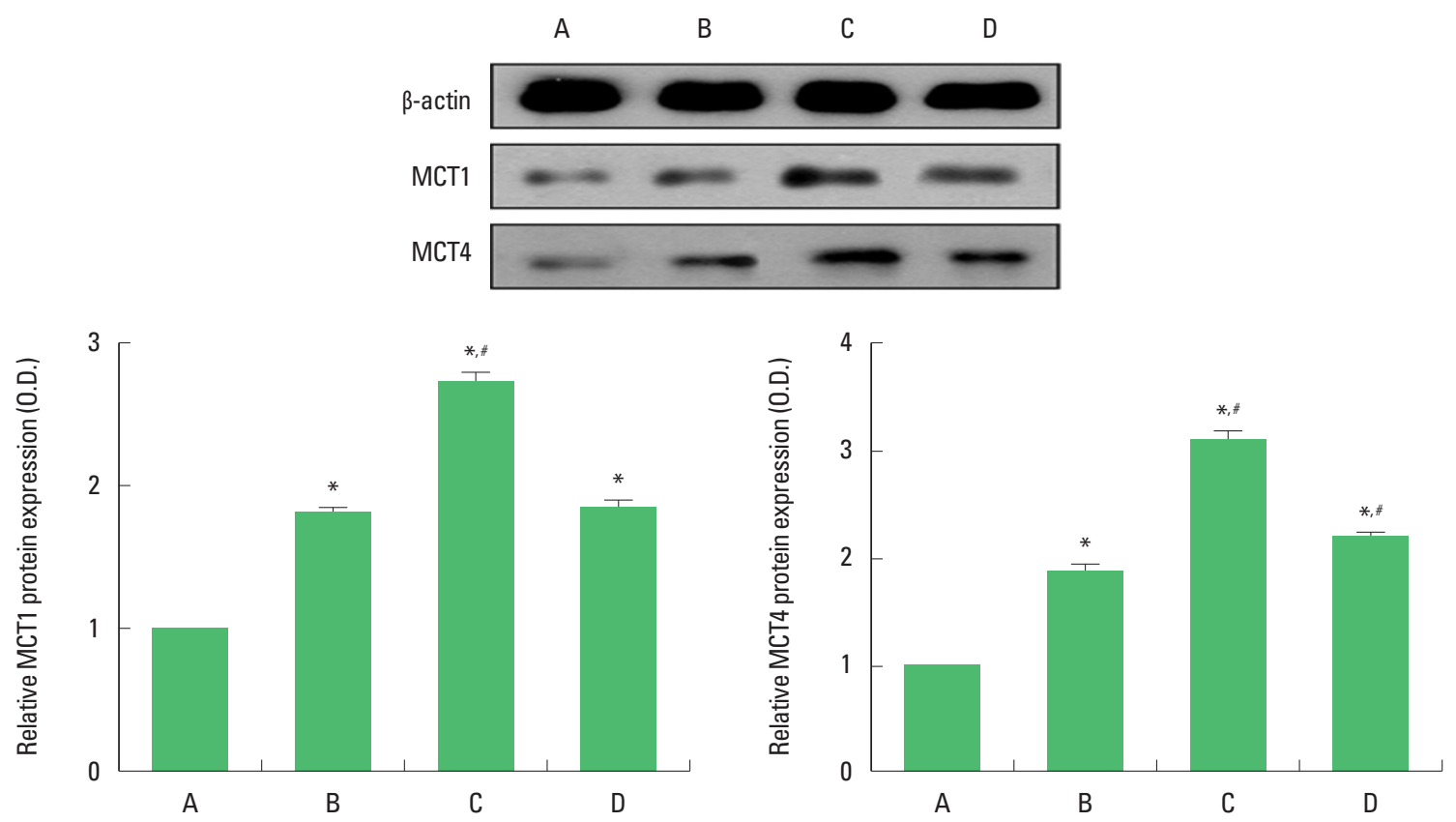

Fig. 3. Effects of sildenafil citrate on monocarboxylate transporter (MCT)1 and MCT4 expressions in the gastrocnemius muscles. A, control group; $B$, exhaustive exercise group; C, exhaustive exercise and 20-mg/kg sildenafil treatment group; D, exhaustive exercise and $40-\mathrm{mg} / \mathrm{kg}$ sildenafil treatment group. ${ }^{*} P<0.05$ compared to the control group. ${ }^{\sharp} P<0.05$ compared to the exhaustive exercise group. 
treatment with sildenafil citrate decreased lactate concentration in the exhaustive swimming exercise rats $(P<0.05)$. The significant suppressing effect appeared in the $20-\mathrm{mg} / \mathrm{kg}$ sildenafil citrate.

\section{Effect of sildenafil citrate on MCT1 and MCT4 expressions in the gastrocnemius}

The MCT1 and MCT4 expressions are shown in Fig. 3. Exhaustive swimming exercise increased MCT1 and MCT4 expressions in the gastrocnemius muscles $(P<0.05)$ and that treatment with sildenafil citrate showed higher MCT1 and MCT4 expressions in the exhaustive swimming exercise rats $(P<0.05)$. The significant enhancing effect appeared in the $20-\mathrm{mg} / \mathrm{kg}$ sildenafil citrate.

\section{Effect of treadmill exercise on nNOS expression in the gastrocnemius muscles}

The nNOS expression are shown in Fig. 4. Exhaustive swimming exercise decreased $\mathrm{nNOS}$ expression in the gastrocnemius muscles $(P<0.05)$ and that treatment with sildenafil citrate increased $\mathrm{nNOS}$ expressions in the exhaustive swimming exercise rats $(P<0.05)$. The significant enhancing effect appeared in the 20-mg/kg sildenafil citrate.
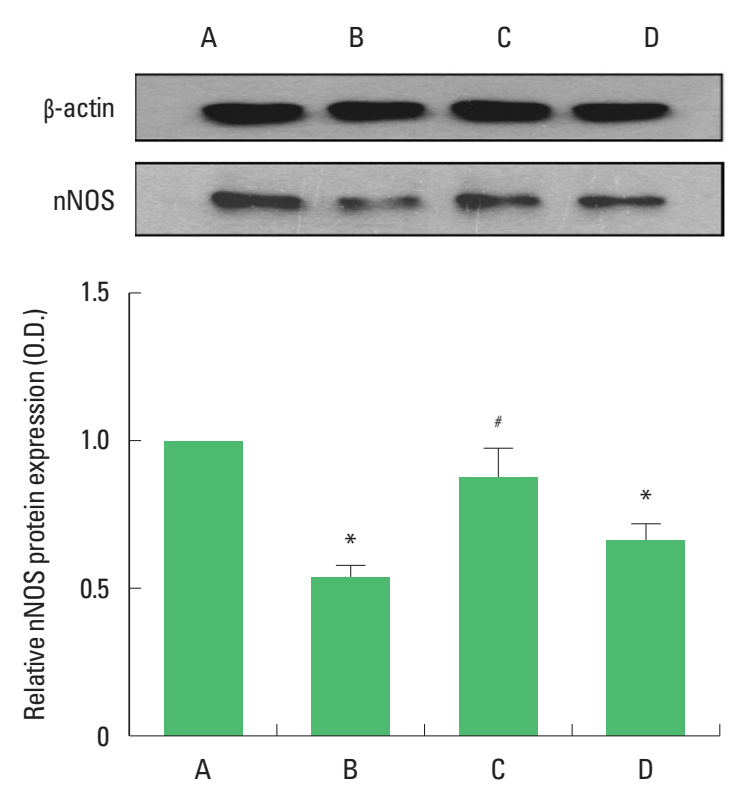

Fig. 4. Effects of sildenafil citrate on neuronal nitric oxide synthase (nNOS) expression in the gastrocnemius muscles. $A$, control group; $B$, exhaustive exercise group; $\mathrm{C}$, exhaustive exercise and 20-mg/kg sildenafil treatment group; $\mathrm{D}$, exhaustive exercise and $40-\mathrm{mg} / \mathrm{kg}$ sildenafil treatment group. ${ }^{*} P<0.05 \mathrm{com}$ pared to the control group. ${ }^{\#} P<0.05$ compared to the exhaustive exercise group.

\section{DISCUSSION}

PDE-5 inhibitors are known to improve exercise capacity in patients with systolic heart failure and secondary pulmonary hypertension in normoxia (Lewis et al., 2007) and to decrease pulmonary vascular resistance and increase maximum oxygen uptake or maximum workload in hypoxic normal subjects (Ghofrani et al., 2004; Richalet et al., 2005). Treatment of the muscular dystrophy mutant animals with the sildenafil improved exercise ability and reduced edema within the musculature (Kobayashi et al., 2008). Sabatini et al. (2011) found that acute treatment with PDE-5 inhibitor, tadalafil, improved glucose metabolism through the induction of anaerobic glycolysis with an accompanying decrease of aerobic metabolism. Weigh loaded forced swim test is the most commonly used screening test for antifatigue in animals. Decreased swimming time in weigh loaded forced swim test is reflected a reduction in muscular force or exhaustion of muscle contraction (Zhang et al., 2009). In the present study, treatment of 20-mg sildenafil citrate prolonged exhaustive swimming time. These results indicate that sildenafil citrate improved endurance exercise capacity.

Muscle fatigue in exercise performance is defined as exercise-induced decrease in maximal voluntary force or increasing lactate concentration (Taylor and Gandevia, 2008). Lactate appears to be an important source of systemic energy and plays an important role in the anaerobic exercise. Lactate concentration is regarded as the most important cause of muscle fatigue during exercise (Finsterer, 2012). In the present study, swimming exercise increased lactate concentration in the blood and 20-mg sildenafil citrate alleviated the exhaustive swimming exercise-induced increase of lactate concentration in the blood.

In skeletal muscle, the most important isoforms are MCT1 and MCT4 (Bonen, 2001). Both MCT1 and MCT4 contents have been reported to be associated with net muscle lactate release during submaximal exercise (Bonen, 2001). Acute exercise has been shown to immediately increase MCT1 and MCT4 protein in rats (Coles et al., 2004; Green et al., 2002). Greater MCT1 and MCT4 contents were associated with a reduction of blood lactate concentration (Thomas et al., 2005). In the present study, swimming exercise led to increased MCT1 and MCT4 expressions in the gastrocnemius muscles, and treatment with 20-mg sildenafil citrate further enhanced the expression of MCT1 and MCT4 compared to the untreated exercise group.

nNOS is also a critical regulator of skeletal muscle exercise performance (Percival et al., 2010). The deficiency of nNOS may re- 
sult in fatigue by impaired vasodilation, decreased muscle blood flow, and increased ROS level during exercise. nNOS-deficient muscles exhibit impaired hypertrophic growth, severe weakness, exaggerated fatigue, poor force recovery after exercise (Percival et al., 2010). In addition, improvement of NO-cGMP signaling using PDE-5 inhibitor can reduce post-exercise muscle damage and enhance $\mathrm{nNOS}$ in mdx mice (Asai et al., 2007; Kobayashi et al., 2008). In the present study, swimming exercise led to decreased nNOS expression in the gastrocnemius muscles, and treatment with 20-mg sildenafil citrate enhanced the expression of nNOS compared to the untreated exercise group.

These results may support sildenafil citrate as an ergogenic aid to improve exercise performance. Sildenafil citrate might be proposed as a potential ergogenic aid through antiperipheral fatigue.

\section{CONFLICT OF INTEREST}

No potential conflict of interest relevant to this article was reported.

\section{ACKNOWLEDGMENTS}

This study was supported by the Ministry of Education of the Republic of Korea and the National Research Foundation of Korea (NRF-2017S1A5A8022823).

\section{REFERENCES}

Asai A, Sahani N, Kaneki M, Ouchi Y, Martyn JA, Yasuhara SE. Primary role of functional ischemia, quantitative evidence for the two-hit mechanism, and phosphodiesterase- 5 inhibitor therapy in mouse muscular dystrophy. PLoS One 2007;2:e806.

Benton CR, Campbell SE, Tonouchi M, Hatta H, Bonen A. Monocarboxylate transporters in subsarcolemmal and intermyofibrillar mitochondria. Biochem Biophys Res Commun 2004;323:249-253.

Bonen A. The expression of lactate transporters (MCT1 and MCT4) in heart and muscle. Eur J Appl Physiol 2001;86:6-11.

Calabrese V, Mancuso C, Calvani M, Rizzarelli E, Butterfield DA, Stella AM. Nitric oxide in the central nervous system: neuroprotection versus neurotoxicity. Nat Rev Neurosci 2007;8:766-775.

Coles L, Litt J, Hatta H, Bonen A. Exercise rapidly increases expression of the monocarboxylate transporters MCT1 and MCT4 in rat muscle. J Physiol 2004;561(Pt 1):253-261.

Corbin JD, Francis SH. Pharmacology of phosphodiesterase- 5 inhibitors. Int J Clin Pract 2002;56:453-459.
Di Luigi L, Sgrò P, Baldari C, Gallotta MC, Emerenziani GP, Crescioli C, Bianchini S, Romanelli F, Lenzi A, Guidetti L. The phosphodiesterases type 5 inhibitor tadalafil reduces the activation of the hypothalamus-pituitary-adrenal axis in men during cycle ergometric exercise. Am J Physiol Endocrinol Metab 2012;302:E972-978.

Ding X, Tang K, Lu P, Putheti R. Antifatigue effects of polydatin from Chinese herb Polygonum Cuspidatum in swimming mice. Afr J Microbiol Res 2009;3:358-361.

Faoro V, Lamotte M, Deboeck G, Pavelescu A, Huez S, Guenard H, Martinot JB, Naeije R. Effects of sildenafil on exercise capacity in hypoxic normal subjects. High Alt Med Biol 2007;8:155-163.

Finsterer J. Biomarkers of peripheral muscle fatigue during exercise. BMC Musculoskelet Disord 2012;13:218.

Förstermann U, Sessa WC. Nitric oxide synthases: regulation and function. Eur Heart J 2012;33:829-837d.

Ghofrani HA, Reichenberger F, Kohstall MG, Mrosek EH, Seeger T, Olschewski H, Seeger W, Grimminger F. Sildenafil increased exercise capacity during hypoxia at low altitudes and at Mount Everest base camp: a randomized, double-blind, placebo-controlled crossover trial. Ann Intern Med 2004;141:169-177.

Green H, Halestrap A, Mockett C, O'Toole D, Grant S, Ouyang J. Increases in muscle MCT are associated with reductions in muscle lactate after a single exercise session in humans. Am J Physiol Endocrinol Metab 2002;282:E154-160.

Halestrap AP. The SLC16 gene family - structure, role and regulation in health and disease. Mol Aspects Med 2013;34:337-349.

Hsu AR, Barnholt KE, Grundmann NK, Lin JH, McCallum SW, Friedlander AL. Sildenafil improves cardiac output and exercise performance during acute hypoxia, but not normoxia. J Appl Physiol (1985) 2006; 100:2031-2040.

Kloner RA. Cardiovascular effects of the 3 phosphodiesterase- 5 inhibitors approved for the treatment of erectile dysfunction. Circulation 2004; 110:3149-3155.

Kobayashi YM, Rader EP, Crawford RW, Iyengar NK, Thedens DR, Faulkner JA, Parikh SV, Weiss RM, Chamberlain JS, Moore SA, Campbell $\mathrm{KP}$. Sarcolemma-localized $\mathrm{nNOS}$ is required to maintain activity after mild exercise. Nature 2008;456:511-515.

Lewis GD, Shah R, Shahzad K, Camuso JM, Pappagianopoulos PP, Hung J, Tawakol A, Gerszten RE, Systrom DM, Bloch KD, Semigran MJ. Sildenafil improves exercise capacity and quality of life in patients with systolic heart failure and secondary pulmonary hypertension. Circulation 2007;116:1555-1562.

Olfert IM, Loeckinger A, Treml B, Faulhaber M, Flatz M, Burtscher M, Truebsbach S, Kleinsasser A. Sildenafil and bosentan improve arterial oxygenation during acute hypoxic exercise: a controlled laboratory 
trial. Wilderness Environ Med 2011;22:211-221.

Percival JM, Anderson KN, Huang P, Adams ME, Froehner SC. Golgi and sarcolemmal neuronal NOS differentially regulate contraction-induced fatigue and vasoconstriction in exercising mouse skeletal muscle. J Clin Invest 2010;120:816-826.

Ricart A, Maristany J, Fort N, Leal C, Pagés T, Viscor G. Effects of sildenafil on the human response to acute hypoxia and exercise. High Alt Med Biol 2005;6:43-49.

Richalet JP, Gratadour P, Robach P, Pham I, Déchaux M, Joncquiert-Latarjet A, Mollard P, Brugniaux J, Cornolo J. Sildenafil inhibits altitude-induced hypoxemia and pulmonary hypertension. Am J Respir Crit Care Med 2005;171:275-281.

Sabatini S, Sgrò P, Duranti G, Ceci R, Di Luigi L. Tadalafil alters energy metabolism in C2C12 skeletal muscle cells. Acta Biochim Pol 2011;58: 237-241.

Sheffield-Moore M, Wiktorowicz JE, Soman KV, Danesi CP, Kinsky MP, Dillon EL, Randolph KM, Casperson SL, Gore DC, Horstman AM, Lynch JP, Doucet BM, Mettler JA, Ryder JW, Ploutz-Snyder LL, Hsu JW, Jahoor F, Jennings K, White GR, McCammon SD, Durham WJ. Sildenafil increases muscle protein synthesis and reduces muscle fatigue. Clin Transl Sci 2013;6:463-468.
Shin MS, Park SS, Lee JM, Kim TW, Kim YP. Treadmill exercise improves depression-like symptoms by enhancing serotonergic function through upregulation of 5-HT1A expression in the olfactory bulbectomized rats. J Exerc Rehabil 2017;13:36-42.

Stamler JS, Meissner G. Physiology of nitric oxide in skeletal muscle. Physiol Rev 2001;81:209-237.

Sun S, Li H, Chen J, Qian Q. Lactic acid: no longer an inert and end-product of glycolysis. Physiology (Bethesda) 2017;32:453-463.

Taylor JL, Gandevia SC. A comparison of central aspects of fatigue in submaximal and maximal voluntary contractions. J Appl Physiol (1985) 2008;104:542-550.

Thomas C, Perrey S, Lambert K, Hugon G, Mornet D, Mercier J. Monocarboxylate transporters, blood lactate removal after supramaximal exercise, and fatigue indexes in humans. J Appl Physiol (1985) 2005;98: 804-809.

Wan JJ, Qin Z, Wang PY, Sun Y, Liu X. Muscle fatigue: general understanding and treatment. Exp Mol Med 2017;49:e384.

Zhang G, Shirai N, Higuchi T, Suzuki H, Shimizu E. A comparative study of the effects of erabu sea snake (Laticauda semifasciata) lipids, green tea extract and conjugated linoleic acid on the swimming endurance of mice. Int J Vitam Nutr Res 2009;79:362-374. 